\title{
ACESSO DE NEGRAS E NEGROS À PÓS-GRADUAÇÃo
}

\author{
Luiz Alberto Oliveira Gonçalves ${ }^{1}$ \\ Edmilson Antonio Pereira Junior ${ }^{2}$ \\ Francisco Ângelo Coutinho ${ }^{3}$ \\ Juliano Gonçalves Pereira ${ }^{4}$
}

\begin{abstract}
Resumo: Este artigo analisa o acesso à pós-graduação de indivíduos de ambos os sexos pertencentes ao grupo étnico-racial classificado como negros e os compara ao de brancos. Os dados abrangentes sobre a realidade encontrada no país, em relação à presença ou não de negros e de negras na pós-graduação, foram extraídos da Pesquisa Nacional por Amostra de Domicílios (Pnad), desenvolvida pelo Instituto Nacional de Geografia e Estatística (IBGE). É apresentada a fundamentação teórica direcionada à inserção de negras e de negros no nível mais alto de escolaridade: a pós-graduação. Foram investigados o nível de escolarização da população brasileira, em 2004 e 2013, e o acesso de negros e de brancos à pós-graduação no país. Em ambas as análises, foi feita a comparação entre o grupo de negros e o de brancos.
\end{abstract}

Palavras-chave: Negros; Pós-Graduação; Desigualdade Educacional.

\section{ENTRANCE OF BLACK WOMEN AND BLACK MEN TO POSTGRADUATE}

Abstract: This article analyzes the access to postgraduate study of individuals of both sexes belonging to the ethnic-racial group classified as black and compares them to whites. Comprehensive data on the reality found in the country, regarding the presence or absence of blacks and blacks in the postgraduate studies, were extracted from the National Household Sample Survey (PNAD), developed by the National Institute of Geography and Statistics (IBGE). It presents the theoretical foundation directed to the insertion of black women and black men in the highest level of schooling: the postgraduate. The level of enrollment of the Brazilian population in 2004 and 2013 and the access of blacks and whites to postgraduate studies in the country were investigated. In both analyzes the comparison between the group of blacks and the group of whites was made.

Keywords: Blacks; Postgraduate; Educational Inequality.

\section{ACCÈS DE NOIRS ET NOIRS À POSTGRADUATE}

Résumé: Cet article analyse l'accès aux études de troisième cycle des individus des deux sexes appartenant au groupe ethnique-racial classé dans la catégorie des Noirs et les compare aux Blancs. Des données complètes sur la réalité constatée dans le pays concernant la présence ou l'absence de Noirs et de Noirs dans les études de troisième cycle ont été extraites de l'Enquête

\footnotetext{
${ }^{1}$ Professor Titular de Metodologia de Pesquisa do Departamento de Ciências Aplicadas à Educação da FaE/UFMG. E-mail: luiz.goncalves@pq.cnpq.br

${ }^{2}$ Estatístico, doutor em Educação e bolsista de Pós-Doutorado (PNPD/CAPES) na Linha de Políticas Públicas em Educação da FaE/UFMG. E-mail: edmilsonpj@yahoo.com.br

${ }^{3}$ Professor Adjunto do Departamento de Metodologia de Ensino da FaE/UFMG e bolsista do CNPq.

${ }^{4}$ Doutorando em Educação da FaE/UFMG e bolsista de doutorado do CNPq.
} 
nationale par sondage sur les ménages (PNAD), développée par l'Institut national de géographie et de statistique (IBGE). Il présente les fondements théoriques orientés vers l'insertion des Noirs et des Noirs dans le plus haut niveau de scolarité: le troisième cycle. Le niveau d'inscription de la population brésilienne en 2004 et 2013 et l'accès des noirs et des blancs aux études de troisième cycle dans le pays ont été examinés. Dans les deux analyses, la comparaison entre le groupe des noirs et le groupe des blancs a été faite.

Mots-clés: Les noirs; Postgraduate; Inégalité Éducative.

\section{ACCESO DE NEGRAS Y NEGROS A LA POST-GRADUACIÓN}

Resumen: Este artículo analiza el acceso al posgrado de individuos de ambos sexos pertenecientes al grupo étnico-racial clasificado como negros y los compara al de blancos. Los datos completos sobre la realidad encontrada en el país, en relación a la presencia o no de negros y de negras en el posgrado, fueron extraídos de la Encuesta Nacional por Muestra de Domicilios (PNAD), desarrollada por el Instituto Nacional de Geografía y Estadística (IBGE). Se presenta la fundamentación teórica dirigida a la inserción de negras y de negros en el nivel más alto de escolaridad: la posgrado. Se investigó el nivel de escolarización de la población brasileña, en 2004 y 2013, y el acceso de negros y de blancos al posgrado en el país. En ambos análisis se hizo la comparación entre el grupo de negros y el de blancos.

Palabras-clave: Negros; Posgrado; Desigualdad Educativa.

Este artigo descreve os resultados da pesquisa Negras e Negros nas Ciências, financiada pela Fundação Carlos Chagas (FCC), com o apoio da Fundação Ford, que analisou o acesso à pós-graduação de indivíduos de ambos os sexos pertencentes ao grupo étnico-racial classificado como negros e os compara ao de brancos. Os dados abrangentes sobre a realidade encontrada no país, em relação à presença ou não de negros e de negras na pós-graduação, foram extraídos da Pesquisa Nacional por Amostra de Domicílios (Pnad), desenvolvida pelo Instituto Nacional de Geografia e Estatística (IBGE). Converge com a linha de pesquisa 3 do referido edital de concurso que propunha estudos quantitativos que explorassem as bases de dados disponibilizadas por instituições de pesquisa.

A pós-graduação, sobretudo o mestrado e o doutorado, é uma área extremamente disputada. Inúmeras teorias acerca da seletividade social no sistema de ensino apontam diferentes argumentos e destacam variáveis que atuam como filtros para dificultar a entrada de pessoas nesse universo intelectual. Tal discussão restringia-se à classe social, mas depois se descobriu que esta camuflava outras categorias com igual poder de seleção excludente: gênero; raça ou etnia; nacionalidade; sexualidade; religiosidade; entre outras. 
Em suma, a influência do grupo étnico-racial no nível de escolaridade dos indivíduos não é nenhuma novidade. A pura constatação dessa diferenciação somente confirma o que todos nós já sabemos. Entretanto, esses resultados desvelam outros problemas que certamente já existiam, mas ficavam invisíveis e até silenciados.

Por exemplo, as políticas de ações afirmativas pressupõem, obrigatoriamente, que para atingir o objetivo de inserir negras e negros nas universidades públicas, estas teriam que pensar forçosamente na expansão de vagas e de condições materiais para que esse processo se realize com qualidade. Por essa razão, analisar a viabilidade financeira da gestão pública brasileira para garantir o aumento de negros e negras na universidade exige que se considere nos estudos os embates na área da política orçamentária identificando como esta viabiliza ou não recursos para que a demanda dos movimentos negros por educação se realize efetivamente (Grisa; Caprara, 2016).

Esse processo político que se arrasta desde o final do século $\mathrm{XX}$ tomou trajetórias muito conturbadas no Brasil. Tal processo foi fortalecido pelas pressões internacionais pós-Durban que exigia que os governos nacionais garantissem gratuitamente educação, sobretudo, para os setores mais excluídos da sociedade. Analisando esse tipo de embate, logo no início do século XXI, Rosana Heringer (2011) retratou fatos que marcaram, feliz e dolorosamente, a luta dos movimentos negros iniciada na nova gestão presidencial, em 2003. Em outubro desse mesmo ano, criou-se, em nível federal, um Grupo de Trabalho Interministerial (GTI), reunindo 11 ministérios, o Conselho Nacional de Educação e a Advocacia-Geral da União com o objetivo de fazer um levantamento completo dos dados sobre desigualdades raciais e étnicas no ensino brasileiro e propor uma política de acesso para afrodescendentes ao ensino superior.

Parecia que tudo ia bem. Houve um avanço, pois o Ministério da Educação entregou à Casa Civil uma proposta de Medida Provisória, autorizando as universidades públicas a adotarem cotas. Tomava-se, assim, todas as medidas legais para legitimar essa política em todo o país, evitando-se "futuras contestações judiciais e processos" (Heringer, 2011).

Até aqui, registrava-se uma vitória do movimento negro, lembrando que, naquele momento, estava formada a Secretaria Especial de Políticas da Promoção da 
Igualdade Racial (SEPPIR) que, de certa forma, comandava todo aquele debate em nível federal. Para gerenciar a implantação dessa política de equidade racial criou-se o Programa de Ações Afirmativas para Acesso e Permanência de Negros nas Universidades (PRO-NEGRO), que tinha como objetivo incentivar e auxiliar tecnicamente as universidades na implantação desse programa. Outro aspecto importante incorporado ao PRO-NEGRO era que esse abarcava cotas no ensino médio federal, que, na realidade era considerado, também, como um sério gargalo para a inserção dos (as) negros (as) na educação (Gonçalves, 2011).

Eram dois os critérios para que futuros(as) estudantes negros e negras pudessem participar do PRO-NEGRO: autodeclaração racial e uma pontuação mínima a ser atingida para se beneficiar das cotas. No momento em que tudo se preparava para ser encaminhado pelo Presidente da República ao Congresso Nacional sob a forma de projeto de lei, houve uma radical mudança ministerial, em fevereiro de 2004, com a entrada de um novo ministro da Educação que se "manifestou contrário às cotas". Segundo Heringer, o ministro alegava que

[...] as mesmas são insuficientes para garantir o acesso dos grupos excluídos à educação superior. (Assim) algumas semanas após assumir a pasta, o ministro apresenta uma proposta nova para discussão: o aproveitamento de cerca de 100 mil vagas ociosas nas universidades privadas a serem ocupadas por estudantes negros, indígenas, portadores de deficiência e ex-presidiários, já a partir de 2004. Este número representaria $25 \%$ das vagas disponíveis nas universidades privadas, que estariam com $37,5 \%$ de vagas ociosas. A contrapartida do governo seria um plano de renúncia fiscal que beneficiaria as universidades privadas que adotassem o sistema. (2011, p. 295)

Contrariamente à conquista da concessão das cotas para negras e negros no ensino superior, ao que se assiste, nesse momento e com essas medidas ministeriais, se caracterizava como uma derrota do movimento negro. A privatização da educação superior, incluindo a pós-graduação, proposta naquele momento pelo governo federal gerou enorme reação crítica de pesquisadores vinculados à Associação Nacional de Docentes do Ensino Superior (Andes) (Taffarell, 2004; Maués, 2004; Pascual, 2004; Lampert, 2004).

A maioria das críticas que surgiu desse movimento da Andes concentrou-se nos riscos que essas medidas governamentais já anunciavam nas suas formulações relacionadas à privatização do ensino superior e da pós-graduação. Por exemplo, no 
dizer de Olgaíses Maués (2004), a lógica do Programa Universidade para Todos (Prouni) já representava essa "intencionalidade de privatização, mercantilização e submissão da educação ao mercado, deixando a mesma de ser um direito para ser uma mercadoria altamente competitiva" (p. 31).

É nítido o descompasso entre as ações que ocorrem dentro das universidades e as decisões posteriores que o sistema gestor público veio assumir. Isso tem sido uma constante na realidade brasileira e que acaba se naturalizando de forma prejudicial. Há registros importantes feitos por pesquisadores e acadêmicos que mostram no início do século XXI movimentos internos em suas universidades liderados por eles com intuito de começar a sensibilizar a gestão universitária a incorporar as ações afirmativas em suas pós-graduação (Magalhães, 2009).

Sobre o campo da pesquisa atual, temos conceitos e dados para identificar e analisar a presença de negras e negros na pós-graduação no Brasil, ou seja, no nível mais alto da formação acadêmica, destinado, até algum tempo atrás, a jovens e a adultos majoritariamente brancos e das classes dominantes brasileiras. Trata-se, assim, de um espaço a que, em passado muito recente, apenas um seletivo grupo das classes dirigentes poderia acedê-lo. Considerando o significado simbólico, em termos acadêmicos, do status que gera este tipo de posição social, ainda que minoritário quando comparado com o total da população negra no Brasil, entendemos que precisávamos de uma sustentação teórica que nos ajudasse a detectar os fatores que estão implícitos nessa visível inserção de negras e negros em uma posição marcada por alta estratificação social.

Quais teorias poderiam nos ajudar a explicar o fato de termos encontrado, como veremos mais à frente, um pequeno, mas crescente número de negras e negros nos cursos de pós-graduação?

Antes de responder essa questão, é preciso ressaltar um material que nos foi muito precioso e com o qual dialogamos intensamente: trata-se do Relatório Final de Pesquisa da Fundação Carlos Chagas intitulado Desigualdades de Cor/Raça e Sexo entre Pessoas que Frequentam e Titulados na Pós-Graduação: 2000-2010 (Fundação Carlos Chagas - FCC, 2015). Por ser uma pesquisa que faz uma síntese importante, pode-se dizer inédita acerca da questão da equidade racial na pós-graduação brasileira, 
certamente o nosso estudo a tomou como roteiro pelas premissas que vão sendo apontadas ao longo de seu percurso que mostra a diversidade de posições que foram tomadas para se discutir a desigualdade racial no Brasil.

O presente estudo se encontra organizado em três seções, além das considerações finais. A primeira seção apresenta a fundamentação teórica que deu sustentação à análise sobre a inserção de negras e de negros nas instituições de pósgraduação no país. A segunda descreve a fonte de dados utilizada. A quarta seção traz os resultados de dois aspectos centrais: i) o nível de escolarização da população brasileira nos anos de 2004 e de 2013; e ii) o acesso de negros e brancos à pósgraduação no país. Ambos fazem a comparação entre o grupo de negros e de brancos.

\section{FUNDAMENTAÇÃO TEÓRICA}

As teorias predominantes no Brasil para explicar a inserção de negros na pósgraduação vêm de sociólogos de diferentes matizes teóricas que desenvolveram o tema da "integração do negro na sociedade de classes". O destaque é feito à obra de Florestan Fernandes (1964), que criticou a forma como a sociedade brasileira, por meio de sua elite dominante, cria mecanismos para integrar os negros socialmente sem, contudo, afastar critérios e valores do mundo colonial escravista e imperial.

A nosso ver, quando se usa em pesquisa a palavra integração, com ou sem adjetivação, torna-se necessário explicitá-la. O relatório da FCC, citado na seção introdutória, mostrou que a pós-graduação foi ou está sendo o último bastião dominado pela elite brasileira no campo da educação a se abrir a essa discussão. Ela, de certa forma, vem se abrindo muito lentamente para incorporar não só o tema no conteúdo de suas pesquisas como tem tido, em termos de composição estrutural de núcleos de pesquisa, de grupos de trabalho, de quadro docente e, assim por diante, a dificuldade de encontrar formas de ampliar a inserção de negras e negros na área da ciência de forma que cesse a famosa ideia da invisibilidade da população negra nas tomadas de decisões acadêmicas e no universo da produção do conhecimento. Não temos dúvida de que essa ideia, que perpassa parte do relatório da FCC, está condicionada, em grande parte, pelo tipo de material que compôs a sua coleta de dados e interpretação. Essa ausência de negros e negras na pós-graduação foi registrada no referido relatório, tanto na leitura que foi feita em trabalhos acadêmicos quanto em textos legais, como, por exemplo, no 
Estatuto da Desigualdade Racial (2010) e até mesmo na Lei de Cotas para o Ensino Superior (2012). Esta nada fala da pós-graduação (FCC, 2015, p. 2).

Mas há um aspecto que vale ressaltar. Essa ausência da temática étnico-racial na pós-graduação teve espaço na pós-graduação em São Paulo. Aliás, o relatório FCC faz uma rápida menção ao primeiro mestrado em sociologia no Brasil com "a participação de pesquisadores estrangeiros" (FCC, 2015, p. 7). Faltou dizer, no entanto, que um dos estrangeiros que despontou naquele programa e dirigiu várias pesquisas com a temática étnico-racial foi Donald Pierson, entre 1935 e 1950. Do núcleo de Robert Park, da Escola de Chicago, Pierson veio ao Brasil e aqui implantou, pela primeira vez, a Sociologia das relações raciais a partir de 1939. A questão racial estava impregnada na sua formação. Esse era o tema que despontava nos Estados Unidos em cidades industriais, com alta rotatividade de minorias étnicas. Embora estivesse em uma cidade brasileira, já naquele momento se industrializando rapidamente, a sua pesquisa sobre relações étnico-raciais foi em Salvador (BA). O que queríamos ressaltar com essa informação é que as pesquisas na pós-graduação que, naquele momento, tratavam das questões étnico-raciais, eram, na sua maioria, realizadas por pesquisadores brancos. Apenas para lembrar, a dissertação de mestrado de um dos nossos grandes mentores da sociologia, Florestan Fernandes, foi na Escola de Sociologia e Política de São Paulo, que, aliás, era o primeiro mestrado de Sociologia da época, no Brasil. E ainda, a sua dissertação - consagrada pelos expoentes da sociologia estadunidense Robert King Merton e Talcott Parson - se intitulava Função Social da Guerra em uma Sociedade Tupinambá, na qual aplicou com rigor e primor o método funcionalista da teoria social. Depois, Florestan Fernandes foi para a Universidade de São Paulo e lá, sim, em parceria com Roger Bastide, desencadeou um pool de pesquisas no Brasil, em especial na região Sul (Santa Catarina e Rio Grande do Sul), com orientandos célebres que se tornaram pesquisadores das ciências sociais e de referência da área no país. Desafiados pela Organização das Nações Unidas para a Educação, a Ciência e a Cultura (Unesco), após os horrores do racismo da Segunda Guerra Mundial, e financiados pelo referido organismo internacional, buscaram mostrar que a imagem do Brasil, no exterior, como um paraíso racial, era uma farsa. Decidiram estudar especialmente as regiões do país que experimentaram uma enorme vaga de imigrantes europeus, cujos resultados 
falaremos mais à frente (Cardoso, 1960a; 1960b; Ianni, 1958a; 1958b; 1961; Cardoso; Ianni, 1960).

É nesse contexto e nesse clima que se fortaleceu no Brasil o tema da integração social associado à questão da construção da nacionalidade brasileira. O que se queria dizer com o tema da integração? Na sua acepção literal, destacou Mariosa (2003), o termo significa partes ou elementos dispersos que se unem, se integram para formar um todo inteiro e coerente. Quando analisamos o conjunto das diversas áreas da Ciência, como Física, Química, Biologia e Matemática, parece que é esse o sentido dado ao termo. No campo da Sociologia, concebe-se o referido conceito quase da mesma forma que é utilizado nas ciências acima, destacando-se, entretanto, que, para a área sociológica do conhecimento, a integração social é uma noção que se circunscreve à vida coletiva. Esse termo, nesse contexto, refere-se a processos que vinculam, legitimam e criam reciprocidades e hierarquias entre as estruturas e as instituições sociais. Resumindo: conceito de integração social pressupõe "a internalização de crenças, costumes, valores adaptação, educação, instrução e todo processo que tem por finalidade adestrar o indivíduo para ocupar um lugar dentro de uma estrutura préexistente à sociedade" (Mariosa, 2003, p. 37).

Como anteriormente dito, o conceito de integração dos negros na sociedade brasileira, tal como analisado por Fernandes, manteve crenças e valores coloniais que acabaram persistindo ao longo do século XX. Antônio Sérgio Guimarães, em seu instigante texto sobre Intelectuais Negros e Formas de Integração Nacional (2004), analisando os diferentes modos de inserção social dos negros, identificou, na produção sobre esse tema, um certo consenso que predominou na literatura sobre relações raciais no Brasil. O referido consenso tinha como suporte um entendimento persistente de que "eminentes escritores descendentes de africanos no Brasil", desde a primeira metade do século XIX e, em uma boa parte inicial do século XX, estavam, de certa forma, integrados socialmente, por intermédio da "ideologia do embranquecimento". (Guimarães, 2004, p.271-272).

$\mathrm{O}$ ideal de branqueamento, segundo alguns autores, teve, e ainda tem tido no século XXI, um papel decisivo na discussão sobre a classificação étnico-racial no Brasil (Bento, 2002; Munanga, 2004). Ele funciona como um dispositivo, ou seja, como uma 
ferramenta que molda os pensamentos e as formas comunicativas. Ele orienta as trocas de significados entre as pessoas e, ainda, entre os grupos e as organizações sociais. A força desse ideal de branqueamento levou alguns pensadores no século XX a formular uma sociologia das ausências, sugerindo que grupos escravizados e inferiorizados ficavam invisíveis. Estudos sobre o mundo intelectual brasileiro, na passagem do século XIX para o século XX, mostram como a elite brasileira tomava os poucos exemplos de afro-brasileiros que acederam ao mundo das Letras, da Literatura e do Jornalismo como símbolos do branqueamento. Como a maioria deles eram mestiços, filhos de negros ou negras com brancas ou brancos, aquele resultado obtido em suas vidas era visto como uma herança da supremacia branca.

Segundo Guimarães (2004), esses escritores eram classificados, segundo os padrões da época, como "mulatos". Entre eles, estavam "Aleijadinho (1780-1814), Luis Gama (1830-1882), José do Patrocínio (1854-1909), Lima Barreto (1881-1927), Mario de Andrade (1893-1945) e outros. Quando se lê a obra desses autores, realmente todos afro-descendentes, fica claro que eles não estavam nem invisíveis nem ausentes dos debates sobre a condição do negro. Talvez o que ocorria era muito mais uma sociologia da cegueira que insistia em não os ver.

Antônio Sergio Guimarães introduziu, na teoria da integração social da população negra no Brasil, a ideologia do embranquecimento e, com ela, propôs, em cena, uma das complexidades do problema da classificação étnico-racial no Brasil. Ainda, mostrou que pesquisas, como esta que estamos realizando, têm, forçosamente, de levar em conta, como uma das varáveis centrais do estudo tem sido definida. Quem a define? É o próprio sujeito? Ou é o recenseador que decide classificar a cor do outro de acordo com os critérios que vigoram no pensamento social da época da coleta dos dados? Não se pode esquecer que o pertencimento étnico-racial dos indivíduos considerado nos dados, por nós, analisados necessita claramente de explicações.

A classificação racial, seja hétero ou autoclassificatória, está profundamente condicionada ao contexto sócio-histórico e cultural em que ela se produz para estabelecer códigos de estratificações que localizam o indivíduo segundo o seu pertencimento étnico-racial em escalas altamente hierarquizadas. A esse problema associa-se o tema do embranquecimento ao qual nos referimos acima, pelo fato de ele 
ter estabelecido a cor branca como o padrão para classificar a cor dos não-brancos segundo uma escala hierárquica.

Analisando a demografia da cor no Brasil, Sergei Soares (2009) mostrou, claramente, como a ideologia do embranquecimento foi utilizada como uma estratégia do poder dominante para mudar a imagem do Brasil sob o ponto de vista da cor da sua população. Entretanto, esse dispositivo funcionou entre os censos de 1890 e 1940. No primeiro registro, o Brasil é um país mais negro. Dois anos após a libertação da escravatura, apontava-se que $56 \%$ dos brasileiros eram pretos. Naquele momento, a população foi classificada nas seguintes categorias: branco, preto, mestiço ou caboclo. Mas essa classificação era muito mais detalhada, como mostrou a historiadora Célia Maria Marinho do Azevedo (1987), ao analisar documentos de textos escritos por partidários de doutrinas racialistas construídas no século XIX. Para estes, o embranquecimento era o projeto que as elites queriam implantar no Brasil. Azevedo recuperou depoimentos publicados na época por pessoas proeminentes, que ocupavam cargos públicos na condição de professores de ensino superior, alguns com encargos legislativos.

O Censo de 1890 revelava ser o Brasil uma república incrivelmente enegrecida, que se lançou à primeira ação impulsionada pela câmara dos deputados para branquear o país de forma progressiva. A estratégia era reverter a lógica original fundada na escravatura que aumentou o número de negros para o trabalho na condição de escravizados. Célia Maria do Azevedo destaca que, a partir da abolição, "o negro sai de cena sendo substituído pelo imigrante europeu". Com troca de personagens históricos, "introduzem-se novos temas com base em uma população essencialmente estrangeira" (Azevedo, 1987, p. 21).

Dando sequência à análise do artigo de Sergei Soares (2009), fica claro que o autor identifica em seus dados uma grande reversão. O Brasil enegrecido de 1890 havia embranquecido, em 1940. As teorias racialistas que orientavam as classificações étnicoraciais se refletiam nos levantamentos censitários. Em 1940, a taxa de negros cai para $37,5 \%$, enquanto os brancos crescem significativamente mais de $50 \%$.

Comparando os dois períodos, Soares identificou um fator comum para explicar porque em 1890 o país expressava um enegrecimento e em 1940 ocorria o inverso, 
passando a ser um país cada vez mais embranquecido. Nos dois casos, houve uma ação pública provocada por movimentos migratórios. Na primeira, acentua-se o aumento da população da África negra. Na segunda, 1940, observa-se o resultado da vinda massiva de imigração, mas dessa vez, de brancos europeus (Soares, 2009, p. 99).

Possivelmente, os movimentos imigratórios interferiram nos dados do recenseamento realizados, nos dois períodos considerados acima. Outros estudos que não seguiram nenhuma matriz estatística sustentaram, de certa forma, a hipótese de que o translado de africano e depois de europeus para o Brasil mudaram o perfil étnicoracial da sociedade brasileira, cujos conteúdos aparecem em documentos, em reportagens, legislações e assim por diante. Um exemplo desse tipo de estudo já apresentado acima foi realizado por Azevedo (1987). Ao analisar a ideologia racial das elites no século XIX, a autora oferece um importante repertório de dados que mostram como a abertura dos portos para entrada de imigrantes europeus no Brasil trouxe mudanças na classificação étnico-racial da sociedade brasileira.

Esse movimento de buscar embranquecer - imaginária e ideologicamente - o povo brasileiro teve, como se pode ver, nas várias observações feitas acima por autores de diferentes formações, um espaço na pauta dos debates que envolveram. Envolveram não só políticos com influência regional e nacional, como, também, importantes intelectuais que disputaram e disputam ferrenhamente, no cenário nacional e internacional, a imagem que querem construir das relações étnico-raciais brasileiras.

Um ponto comum que envolve todos os debatedores tem a ver com a presença no Brasil de teóricos europeus, como, por exemplo, Conde de Gobineau e Louis Agassiz, que construíram, por meio de suas produções consideradas racistas, um quadro depreciativo da população brasileira. Ambos tiveram uma acolhida da corte portuguesa, instalada na época no Brasil, e foi para esta que eles apresentaram as suas posições rotuladas de científicas, nas quais descreviam os mestiços de brancos com negros como verdadeiras degenerescências da raça humana.

Foi em torno dessas ideias "racialistas" que intelectuais brasileiros se mobilizaram, seja para apoiá-las, para refutá-las ou até mesmo para adaptá-las ao contexto brasileiro, retirando de seu escopo aquilo que não cabia no cenário nacional. Esse retrato de confrontos e acertos entre os intelectuais e os debates nas academias com 
especialistas e militantes de movimentos sociais já estão bem documentados e há uma literatura ampla sobre o tema.

Vale, entretanto, ressaltar o momento em que estamos investigando o perfil de indivíduos de ambos os sexos que tiveram de responder em levantamentos de caráter censitário ou amostral como classificavam ou, mais precisamente, nomeavam a cor de sua pele. Isso poderia ser uma ação simples e descomplicada se não existissem as questões racialistas acima levantadas. Ter que responder a essa questão em uma sociedade na qual representações hierárquicas sobre as diferentes classificações étnicoraciais são medidas com base no padrão branco, muito possivelmente essa autodefinição deve ter produzido algum mal-estar entre os respondentes e até mesmo para o recenseador, no momento em que estava se processando o censo ou a amostra de domicílio.

Mesmo admitindo-se que se trata de uma autoclassificação, o recenseador tem a sua leitura pessoal quanto ao pertencimento étnico-racial de seu entrevistado. Por vezes, a auto (do respondente) e a hétero (de quem faz a pergunta) classificações se chocam. Se os indicadores preto e branco (dicotomizados) são tomados como o critério de distinção com o qual irá se operar a análise dos dados coletados, vê-se que aqui poderá haver alguns problemas, quando se trata de sujeitos que são de famílias com pai e mãe com pertencimentos raciais diferentes.

Imagine, por exemplo, como fica a questão da classificação na diversidade de tipos que se encontram na categoria mestiço em uma sociedade cuja representação que predominou durante séculos foi a da supremacia do branco erigida como um espelho ao qual todos devem se mirar.

O que importa ressaltar, na presente fundamentação teórica, se relaciona aos conceitos que foram adotados para analisar os dados coletados ao longo deste estudo. Na realidade, o conceito que aparece na Pnad é o da "cor" da pele. Quem declara a cor deveria ser cada um dos indivíduos que moram no domicílio recenseado. Mas não é assim que acontece.

Teoricamente, neste estudo, consideramos o conceito "cor" afastando-nos do uso isolado da característica genética, seja da mãe ou do pai. Seguimos os passos apresentados pelo demógrafo da cor, Sergei Soares, recuperando uma ampla gama de 
estudos que, nos últimos anos, vêm trabalhando com o tema e caracterizando a cor da seguinte maneira:

A cor não é uma herança, mas, sim, uma construção social baseada parcialmente em características genéticas herdadas da mãe, parcialmente em características herdadas do pai e parcialmente em características socioeconômicas herdadas da família na qual a criança nasce ou adquiridas ao longo da vida. (Soares, 2009, p. 101)

É dessa construção que nasce a enorme diversidade de cor da pele que existe no Brasil há muitos séculos. É esse efeito da miscigenação que tem vigorado e diversificado o perfil étnico-racial de nossa população. Essa constatação, como ressalta Soares (2009, p. 102), foi se acentuando na aplicação da Pnad. A característica básica desse levantamento é que, no seu formulário e nas respostas, é possível identificar a pessoa de referência do domicílio, seus filhos e cônjuges.

Soares (2009) identifica nesse tipo de formulário uma lacuna que, dificilmente, os analistas conseguem preencher. Trata-se do fato de que o reconhecimento da referência do domicílio pode ser o pai ou a mãe. Entretanto, nos dois casos, a única certeza que se tem é de que os filhos são deles, mas é apenas um deles que indica a cor, que pode ser o pai ou mãe original. Assim, aceita-se tacitamente que aquele que foi indicado, na pesquisa de amostra de domicílio, como cônjuge, seja ele ou ela, é incorporado, na análise, como progenitor ou progenitora. Se cada um deles declarar cores diferentes, eles entram como casal misto. Não se pode esquecer que é possível que o respondente pode ser também um filho ou uma filha maior de idade presente no momento em que o recenseador se dirige ao domicílio para coletar os dados. Nesse sentido, é esse respondente que atribui a cor dos membros de sua família. Esse é um viés que precisa ser considerado, pois é impossível de ser corrigido. As possíveis mudanças na demografia racial estarão sempre afetadas por esse momento da coleta. Ter mais ou menos brancos ou negros na população estudada depende dessa classificação.

Soares (2009) destacou que, entre 1999 e 2007, houve uma mudança da estratificação da cor. Estudando as coortes raciais nesse período, o autor mostra com clareza que as taxas de embranquecimento da população brasileira vão caindo gradativamente. Cresce, em contrapartida, o número de pessoas que se identificam como negras (preta e parda). Sua hipótese é que essa mudança no cenário demográfico, 
diferentemente dos movimentos imigratórios, está associada à decisão individual. Aumenta cada vez mais a identificação das pessoas com a raça negra.

Essa mudança de visibilidade ocorre exatamente em um momento em que se aumenta a pressão de movimentos sociais. Na sua observação demográfica, Soares sinaliza que existe um momento datado no qual as taxas do número de negros crescem

Em algum momento, entre 1996 e 2001, há o início de um processo de mudança em como as pessoas se veem. Passam a ter menos vergonha de dizer que são negras; passam a não precisar se branquear para se legitimarem socialmente. Essa mudança é um processo surpreendentemente linear, surpreendentemente claro e, ao que tudo indica, ainda não terminou [...] acredito que essa mudança deva muito à influência do Movimento Negro e àqueles que reverberam na sociedade suas reclamações (Soares, 2009, p116).

O autor apresenta, por fim, alguns indicadores que podem estar por trás daquilo que tem aumentado o número de negros na demografia do país. Não precisa mais se ter vergonha de se dizer negro. Há uma quebra do paradigma da invisibilidade do negro. $\mathrm{O}$ que ocorreu foi muito mais uma sociologia da cegueira eurocêntrica que hoje os movimentos recusam a aceitar. Para Soares,

Na medida em que o debate da identificação racial ganha as páginas dos jornais e a sociedade vê que é um tema legítimo; na medida em que negros são apresentados nas telenovelas como personagens poderosos e não apenas empregados domésticos; na medida em que negros são vistos compondo o Supremo Tribunal Federal e ocupando os mais diversos cargos na política; na medida em que o Movimento Negro sai da marginalidade e ocupa espaços no debate político, a identidade negra sai fortalecida (Soares, 2009, p. 116).

É preciso esclarecer o que se entende por população negra e por população branca. Esta última, como já anunciado acima, fez parte do legado do colonialismo ibérico que inclui todos os seus descendentes, na categoria euro-ocidental, elegendo a cor branca como critério de comparação e de classificação dos grupos sociais nãobrancos. O negro, termo que foi, também, uma invenção eurocêntrica passou por uma série histórica de (re)apropriações até chegar ao sentido afirmativo que hoje tem a palavra afastada de todos significados negativos a ela atribuídos no passado.

No banco de dados que será analisado, a palavra "negro" não existe. Quando se pede para que as pessoas digam qual a sua cor, os questionários oferecem como opção de resposta: preto; pardo; branco; amarelo; ou indígena. A categoria "negro", criada com base nesses dados, engloba o preto e pardo. Só que essa inclusão como, destaca 
Antônio Sergio Guimarães (2004), tem uma dupla significação. De um lado, ela agrega pretos, pardos, mulatos e morenos. Mas, posteriormente, ela passou a ser assumida como um "modo subjetivo de se autodenominar e partilhar com outros a diferença racial em relação aos grupos nacionalmente dominantes" (p. 276). Esse último procedimento, segundo Guimarães, "esconde, entretanto que os modos de se identificar racialmente, assim, como as estratégias de abrigar-se na nacionalidade brasileira, podem ser múltiplas" (p. 274). A multiplicidade aparece nas diferenças regionais e estaduais e isto é um indicador importante quando se analisam as diferenças no aumento das taxas de negros em cada região do Brasil, a partir de dados censitários e/ou amostrais.

Vale sempre lembrar as observações de Sergei Soares sobre o critério de identificação racial hoje no Brasil. Para ele, como são as próprias pessoas que identificam a própria cor,

nada garante que (elas) mantenham a mesma raça ao longo da vida. Mudanças de cor/raça idiossincráticas não afetam o tamanho das populações, mas se há um movimento coerente de uma cor/raça para outra, o perfil racial da população pode mudar em velocidade muito superior ao ritmo secular de nascimentos e mortes que caracteriza boa parte das análises demográfica (Soares, 2009, p. 99).

Por se tratar de autodenominação, há de se considerar que o "modo subjetivo" de autodeclarar a cor é diferente no Nordeste, no Sudeste, no Sul, enfim, em cada uma das regiões do país. E essa diferença pode estar associada à forma como historicamente as classificações raciais para caracterizar os não brancos foi estruturada, como mostram alguns estudos realizados desde o final do século XX (Sansone, 2008; Brandão; Marins, 2007). Essa observação exige que se tenha cuidado ao analisar os dados censitários e os amostrais, conjuntamente. De toda forma, são eles que indicam mudanças que ocorrem nas taxas de crescimento da população segundo a identificação da cor.

Considerando esses diagnósticos, este estudo se debruça a analisar dados da Pnad sobre a entrada de negras e negros na pós-graduação. Como será visto, os dados permitiram averiguar a presença de negras e de negros nas pós-graduações, ou seja, nos mais altos níveis de formação intelectual oferecidos pelos cursos universitários no Brasil. 


\section{FONTES DE DADOS}

Este é um estudo quantitativo que se caracteriza por fornecer um diagnóstico abrangente sobre o acesso de negros e negras à pós-graduação no país. Para tal, foram os microdados provenientes da Pesquisa Nacional por Amostra de Domicílios, anualmente desenvolvida pelo IBGE. A Pnad possui cobertura em todo o país, desde 1981, exceto na área rural da região Norte. Além da representatividade nacional, é representativa das unidades federativas e das (nove) regiões metropolitanas.

O período especificado para a análise se inicia em 2004 e vai até 2014. Esse último ano constituiu a base de dados mais recente que se encontrava disponível no momento de realização do estudo, cuja amostra abrangeu cerca de 150 mil domicílios e mais de 360 mil habitantes de todo o Brasil.

A Pnad constitui a melhor alternativa para a projeção populacional e para a análise de tendências socioeconômicas e demográficas da população brasileira no período entre a realização dos censos populacionais. O questionário utilizado possui estrutura similar ao do Censo Demográfico, abordando áreas como educação, trabalho, rendimento, habitação, migração, entre outras. Especificamente sobre a educação, contém informações como: saber ler e escrever; se frequenta escola ou creche; qual o curso mais elevado que frequentou.

\section{RESULTADOS}

Adiante serão apresentados os resultados do estudo, divididos em duas partes. A primeira a analisa o nível de escolarização da população brasileira em dois períodos distintos: 2004 e 2013. A segunda investiga o acesso da população à pós-graduação, sendo verificada a evolução anual das taxas de acesso e também feita a segregação por unidade federativa. A comparação dos resultados encontrados entre o grupo de negros e o de brancos é realizada em todas as etapas.

\section{NÍVEL DE ESCOLARIZAÇÃO DA POPULAÇÃO BRASILEIRA}

O nível de escolarização da população brasileira foi mensurado com base em uma ordem hierárquica dos diferentes níveis de escolaridade dos indivíduos que fizeram 
parte da amostra. A PNAD incorporou, de certa forma, as etapas de escolarização estabelecidas na Lei de Diretrizes de Base da Educação (LDBEN) (Brasil, 1996).

O indivíduo inicia a sua trajetória escolar na educação infantil e pode chegar até à pós-graduação, no caso, em curso de mestrado ou de doutorado. Foi empregada uma escala ordinal com os seguintes níveis de escolaridade: Educação Infantil; Ensino Fundamental; Ensino Médio; Ensino Superior; e Pós-Graduação (mestrado e doutorado).

Ao distribuir os segmentos de brancos e de negros nos diferentes níveis de escolarização, observa-se que houve mudança na inclusão escolar nos diferentes níveis de ensino entre os anos de 2004 e 2013 (Gráfico 1). Contudo, ainda persistem desigualdades percentuais na inserção entre estudantes negros (as) e brancos (as), sobretudo, no ensino superior e na pós-graduação. Na Educação Infantil, no Ensino Fundamental e no Ensino Médio fica evidente o aumento de matrículas, sobretudo, de estudantes negros (as). Esses dados são retratos feitos em um determinado momento que exprimem o momento da coleta dos dados, ou seja, são dados transversais. Por isso, para confirmamos se aqueles crescimentos dos percentuais de matrículas de crianças negras na Educação Infantil - em 2004 era de 0,58\% e em 2013 chegou a 0,95\% representam mesmo uma diferença na vida daquelas crianças, seriam necessários outros estudos. E eles já estão sendo realizados por pesquisadores (as), interessados em estudar a formação étnico-racial nas práticas das creches e das escolas para as crianças pequenas (Silva; Souza, 2013). 
Gráfico 1. Distribuição de indivíduos brancos e negros de acordo com o nível mais elevado de educação - Brasil - 2004/2013

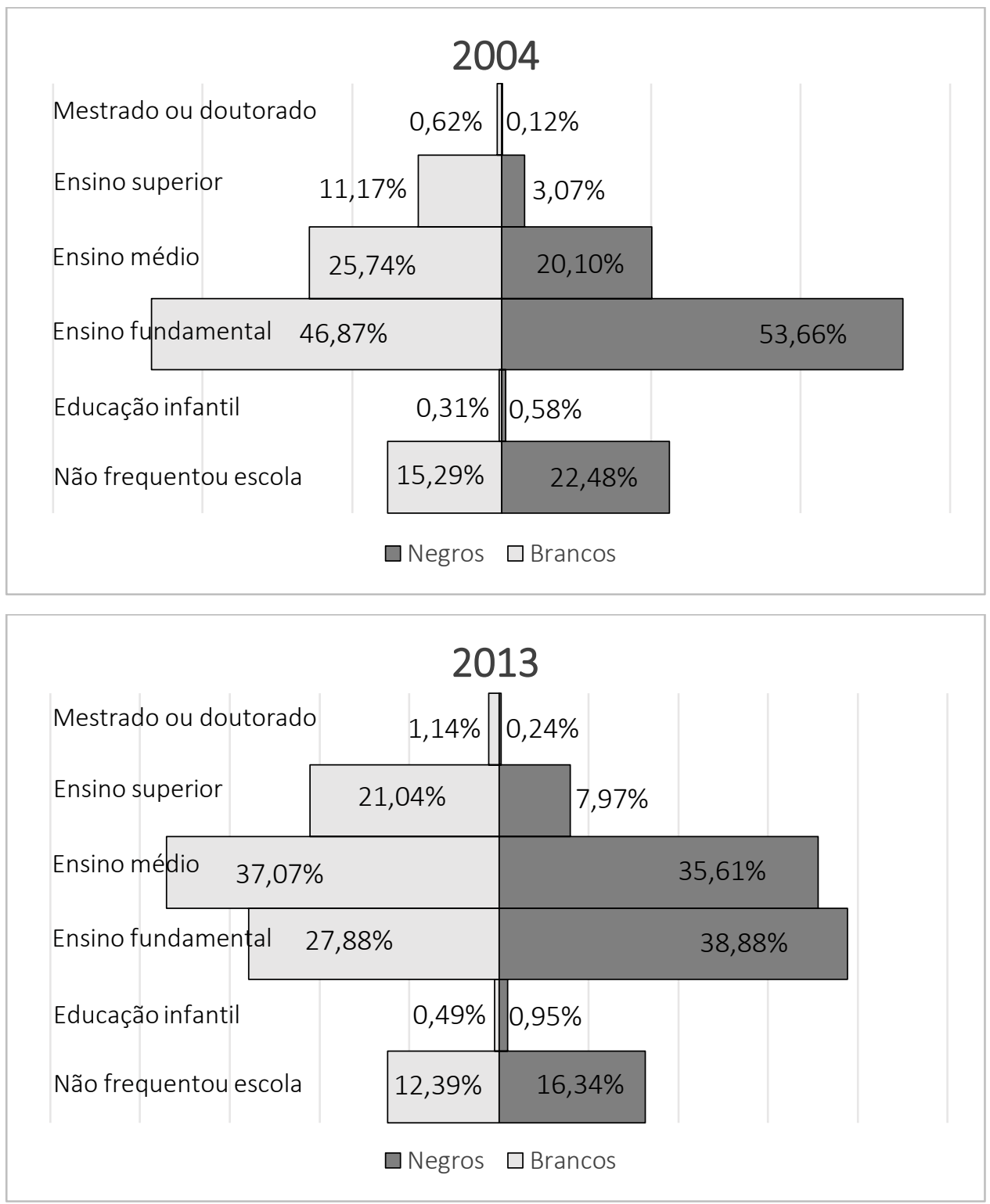

Fonte: Elaboração dos autores, com base nos microdados da Pnad 2004/2013.

Se as taxas de matrículas de negros e de brancos na Educação Infantil cresceram nesses nove anos, o mesmo não aconteceu com o Ensino Fundamental, tanto para população branca (queda de 19\%) quanto para a população negra (com queda de 14,7\%) (Gráfico 1). No Ensino Médio verificou-se aumento das taxas de pessoas nesse nível escolar, comparando-se 2004 e 2013. Houve elevação de 11,33\% em relação aos brancos e de 15,51\% aos negros. Estudos sobre o Ensino Médio no Brasil (Volpi; Silva; Ribeiro, 2014) classificam esse nível de ensino como sendo o grande gargalo na 
mobilidade educacional para os jovens entre 15 e 17 anos no país. O termo "gargalo" é usado no mesmo sentido em que o mundo empresarial aplicava na sua esfera de atuação para descrever um ponto específico dentro da etapa produtiva que empaca, retarda ou encarece a produção. O MEC, na segunda metade do século XX, com base em dados coletados pelo Instituto de Pesquisas Econômicas e Aplicadas (IPEA), atribuiu ao Ensino Médio o rótulo de gargalo para desqualificar ou minimizar as demandas dos movimentos negros relativas ao aumento de vagas ou de ações afirmativas no ensino superior. Antes de se programar políticas para inserção na universidade, alegava o ministério, era preciso romper com o gargalo apresentado pelo Ensino Médio com os seus altos indicadores de repetência e de evasão.

No Ensino Superior, a parcela da população de brancos que possuíam esse nível de escolaridade passou de 11,17\% em 2004 para 21,04\%, em 2013 (Gráfico 1). Também entre os negros houve aumento nessa parcela, passando de 3,07\% para 7,97\%. Embora o crescimento do grupo de pessoas negras com Ensino Superior tenha existido, a elevação entre as pessoas brancas foi ainda maior.

No mais alto nível de escolaridade avaliado pela PNAD, ou seja, na pósgraduação, identificamos o mesmo padrão que em relação ao Ensino Superior. Retomando, embora tenha havido aumento da taxa de negros com pós-graduação, passando de 0,12\% (2004) para 0,24\% (2013), o crescimento foi ainda maior na taxa de pessoas brancas. Entre os brancos, a taxa de 0,62\% subiu para 1,14\% (Gráfico 1).

Esperamos que essa apresentação da distribuição das taxas percentuais de matrículas de brancos (as) e negros (as) nos diferentes níveis de ensino no Brasil, possa ajudar os nossos leitores a situar os contextos nos quais os dados sobre a escolarização da população negra e da população branca foram coletados pela PNAD. Nesse quadro de crescimentos e quedas de matrículas de estudantes nos diferentes níveis de ensino no Brasil, podem-se ver os pequenos percentuais que marcam tanto a matrícula dos (as) brancos (as) quanto a dos negros (as) na pós-graduação, reforçando a imagem da seletividade que esse nível de ensino tem no conjunto do sistema de ensino e no imaginário social. Embora diminuto para ambos os segmentos étnico-raciais, não se pode negar que a população negra se encontra em desvantagem, embora, em 2004 representasse, em termos demográficos, mais de $50 \%$ da população brasileira. 
Destaca-se que, nesse intervalo de 2004 a 2013, surgiram políticas de ações afirmativas propostas pelo governo federal que podem explicar aumentos de matrículas, sobretudo, de negros (as) no ensino superior. O aumento nesse nível de ensino pode ter sido encabeçado por essas políticas. Alguns autores têm estudado e levantado essa hipótese que não descartamos, de forma alguma, ao analisar os resultados dos dados ora analisados. O aumento do número de graduandos (as) negros (as) nas universidades brasileiras já foi incorporado nas avaliações sobre a influência das políticas de ações afirmativas, em vigor desde 2004, mas isso não pode ser estendido acriticamente à pósgraduação. Aqui as transformações visando ao reconhecimento da equidade étnicoracial ainda está muito longe para ser atendido.

\section{ACESSO DE NEGROS E DE BRANCOS À PÓS-GRADUAÇÃo}

A evolução das taxas de inclusão de negros e de brancos nos cursos de pósgraduação no Brasil é apresentada no Gráfico 2. As taxas anuais de frequência dos estudantes de cursos de mestrado ou de doutorado permitem captar a frequência relativa de pós-graduandos em cada período analisado, independentemente do tempo em que cada um está matriculado. Assim, caso tenham existido titulações ou evasões de estudantes nesse intervalo, tais eventos não alteram as referidas medidas. No gráfico, o eixo horizontal (X) representa as variações do tempo, construído em escala anual (20042013). O eixo vertical (Y) apresenta a relação entre o número absoluto de estudantes negros em curso de mestrado ou de doutorado e o número total da população negra no referido período. O mesmo se deu para a população de estudantes brancos, considerando ambos os sexos. 
Gráfico 2. Taxa de pessoas brancas e negras que frequentavam curso de mestrado ou de doutorado - Brasil - 2004-2013
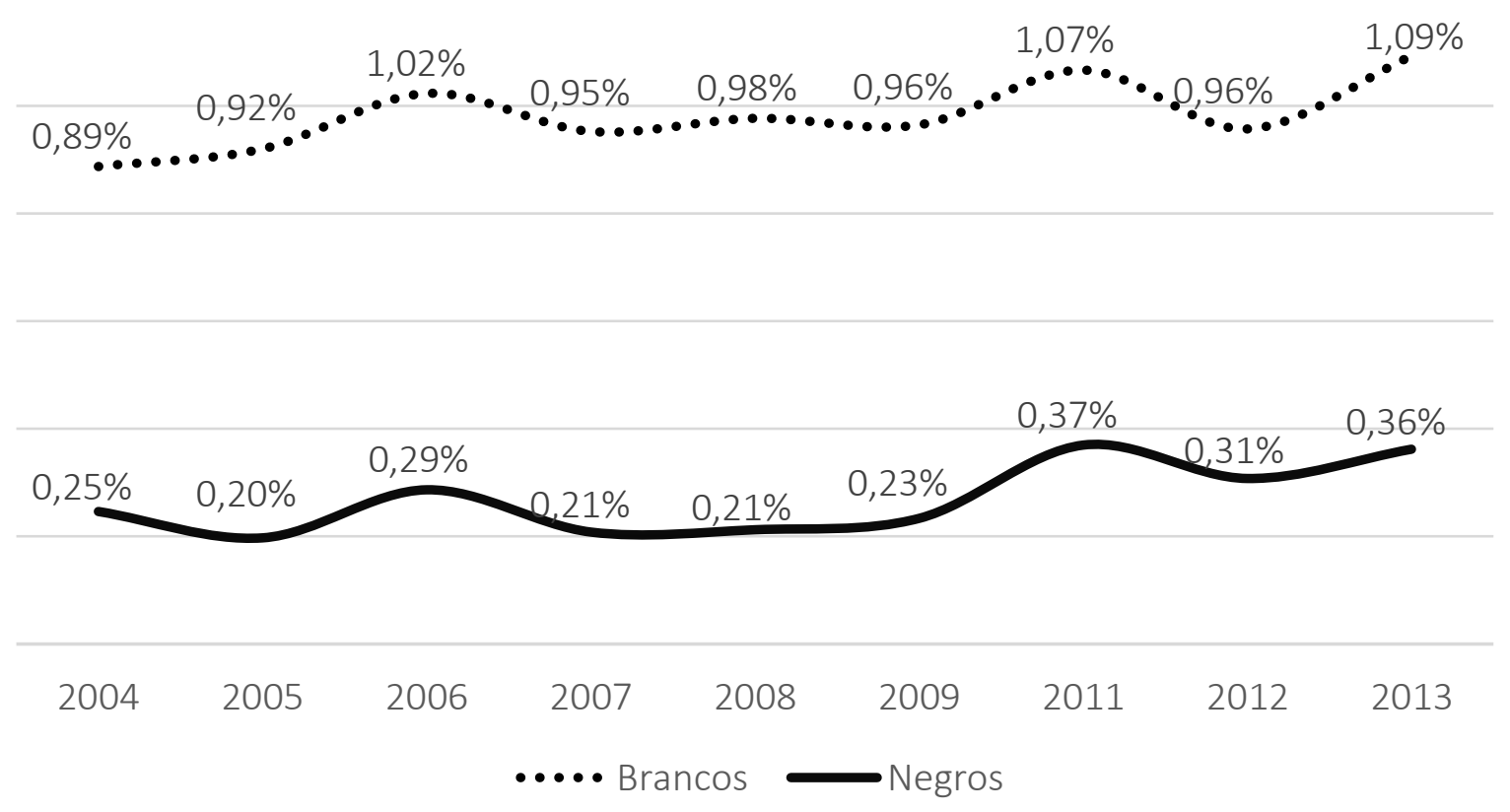

Fonte: Elaboração dos autores, com base nos microdados da PNAD 2004-2013. Nota: Não constam dados referentes ao ano de 2010 devido ao fato de que a PNAD não é realizada nos anos em que ocorre o Censo Demográfico.

Como se pode ver, a posição de cada um dos segmentos analisados - brancos e negros - dentro da pós-graduação se distinguiu ao longo do tempo. As taxas de brancos e negros não partiram de um ponto comum, sendo que as taxas de frequência a cursos de mestrado ou de doutorado relacionadas aos negros foram menores que as taxas do grupo de brancos desde o início. Isso ocorreu em todos os períodos analisados.

Essa disparidade fica melhor assimilada ao aferir a diferença entre as taxas das duas categorias étnico-raciais (negros e brancos), cujos resultados mostraram certa estabilidade ao longo do tempo, variando de 0,64\% a 0,76\% (Tabela 1). Dito de outra forma, apesar das políticas de ações afirmativas desenvolvidas nesse intervalo de tempo, continuaram altíssimas as desigualdades entre negros e brancos na pós-graduação. Entretanto, dentro de cada segmento racial foi possível identificar a instabilidade no número de matrículas ao longo do período analisado (2004-2013). Tanto os brancos quanto os negros apresentaram quedas de taxas nos três últimos anos pesquisados (2011-2013) em comparação aos três primeiros períodos (2004-2006). Porém, as quedas nas matrículas dos (as) estudantes brancos (as) nunca foram inferiores a 0,05\% e entre os negros a queda chegou a $0,17 \%$. Essa persistência das desigualdades entre negros e 
brancos é um indicativo de que o PROUNI e os programas de ações afirmativas, abarcando alunos da graduação, não estavam sendo suficientes para estimular os estudantes negros graduados a seguirem para a pós-graduação.

Ao comparar os dois períodos extremos, o percentual de negras e de negros na pós-graduação no Brasil aumentou, passando significativamente, nesse período de nove anos, de 0,25\% da população desse grupo étnico-racial para 0,36\% (Tabela 1). Entretanto, em relação aos brancos, esse aumento também ocorreu, passando de 0,89\% para 1,09\%. Essa diferença em pontos percentuais mostra que, embora apresentasse o aumento de inserção de negros na pós-graduação, o acesso dos brancos apresentou maior aumento que os negros.

Tabela 1. Taxa de pessoas brancas e negras que frequentavam curso de mestrado ou de doutorado e diferença entre as taxas - Brasil - 2004-2013.

\begin{tabular}{|c|c|c|c|c|c|c|c|c|c|c|}
\hline \multirow{2}{*}{ Cor / Raça } & \multicolumn{2}{|c|}{2004} & \multicolumn{2}{|c|}{2005} & \multicolumn{2}{|c|}{2006} & \multicolumn{2}{|c|}{2007} & \multicolumn{2}{|c|}{2008} \\
\hline & $\mathrm{N}$ & $\%$ & $\mathrm{~N}$ & $\%$ & $\mathrm{~N}$ & $\%$ & $\mathrm{~N}$ & $\%$ & $\mathrm{~N}$ & $\%$ \\
\hline$\overline{\text { Brancos (B) }}$ & 251.170 & 0,89 & \begin{tabular}{|l|}
251.191 \\
\end{tabular} & 0,92 & 280.804 & 1,02 & 259.081 & 0,95 & 261.289 & 0,98 \\
\hline Negros $(\mathrm{N})$ & 72.517 & 0,25 & 59.742 & 0,20 & 88.035 & 0,29 & 63.753 & 0,21 & 65.319 & 0,21 \\
\hline Diferença $(B-N)$ & & 0,64 & & 0,72 & & 0,74 & & 0,74 & & 0,74 \\
\hline \multirow{2}{*}{ Cor / Raça } & \multicolumn{2}{|c|}{2009} & \multicolumn{2}{|c|}{2011} & \multicolumn{2}{|c|}{2012} & \multicolumn{2}{|c|}{2013} & & \\
\hline & $\mathrm{N}$ & $\%$ & $\mathrm{~N}$ & $\%$ & $\mathrm{~N}$ & $\%$ & $\mathrm{~N}$ & $\%$ & & \\
\hline$\overline{\text { Brancos (B) }}$ & 255.156 & 0,96 & 271.060 & 1,07 & 230.657 & 0,96 & 270.654 & 1,09 & & \\
\hline Negros $(\mathrm{N})$ & 72.508 & 0,23 & 111.051 & 0,37 & 94.302 & 0,31 & 112.062 & 0,36 & & \\
\hline Diferença $(B-N)$ & & 0,73 & & 0,70 & & 0,65 & & 0,73 & & \\
\hline
\end{tabular}

Fonte: Elaboração dos autores, com base nos microdados da PNAD 2004-2013. Nota: Não constam dados referentes ao ano de 2010 devido ao fato de que a PNAD não é realizada nos anos em que ocorre o Censo Demográfico.

Adiante será analisada a distribuição de mestrandos e de doutorandos em termos regionais, considerando as matrículas nos programas de pós-graduação de cada estado da federação (Tabela 2). Apareceram as diferenças regionais a que nos referimos anteriormente. Como os dados são autodeclarados e, no Brasil, tivemos uma grande diversidade na própria fase da colonização, as representações do que se chama de branco e de negro são levadas a terem grandes variedades nas suas formulações regionais. De acordo com José Francisco Soares (2015), das 202.717 matrículas registradas, em 2013, em cursos de pós-graduação, 115.001 estavam vinculadas a 
instituições da área federal; 56.094, estadual; 931, municipal; e 31.691 estavam na iniciativa privada. De acordo com o Censo de Ensino Superior de 2013, dos 4.650 cursos de pós-graduação, $51 \%$ estavam na região Sudeste, $20 \%$ na região Sul, $18 \%$ no Nordeste e somente 7,2\% estavam no Centro-Oeste e $4 \%$ na região Norte do país.

Tabela 2. Quantidades absolutas e relativas de brancos e de negros e os respectivos percentuais daqueles que frequentavam curso de mestrado ou de doutorado Brasil - 2013

\begin{tabular}{|c|c|c|c|c|c|c|c|}
\hline \multirow{2}{*}{ Estado da federação } & \multicolumn{3}{|c|}{ Brancos (B) } & \multicolumn{3}{|c|}{ Negros (N) } & \multirow{2}{*}{$\begin{array}{c}\text { Dif. (B - } \\
\text { N) }\end{array}$} \\
\hline & $\mathrm{n}$ & $\%$ & Total & $\mathrm{N}$ & $\%$ & Total & \\
\hline Rondônia & 1.463 & 0,84 & 175.023 & 486 & 0,15 & 329.319 & 0,69 \\
\hline Acre & 174 & 0,28 & 61.318 & 870 & 0,43 & 201.741 & $-0,15$ \\
\hline Amazonas & 587 & 0,20 & 296.826 & 3.233 & 0,33 & 989.070 & $-0,13$ \\
\hline Roraima & 178 & 0,51 & 34.978 & 888 & 0,74 & 119.830 & $-0,23$ \\
\hline Pará & 3.382 & 0,63 & 534.081 & 4.755 & 0,23 & 2.050 .548 & 0,40 \\
\hline Amapá & 1.534 & 2,44 & 62.932 & 1.278 & 0,63 & 201.579 & 1,81 \\
\hline Tocantins & 1.148 & 1,05 & 109.079 & 230 & 0,06 & 358.203 & 0,99 \\
\hline Maranhão & 2.201 & 0,49 & 447.590 & 2.933 & 0,15 & 1.898 .937 & 0,34 \\
\hline Piauí & 1.140 & 0,43 & 266.691 & 2.850 & 0,37 & 761.361 & 0,06 \\
\hline Ceará & 3.568 & 0,44 & 814.780 & 7.775 & 0,43 & 1.791 .252 & 0,01 \\
\hline Rio Grande do Norte & 2.669 & 0,64 & 419.809 & 4.005 & 0,72 & 555.923 & $-0,08$ \\
\hline Paraíba & 5.700 & 1,38 & 413.609 & 4.436 & 0,61 & 732.855 & 0,77 \\
\hline Pernambuco & 12.858 & 1,47 & 876.421 & 5.419 & 0,32 & 1.701 .748 & 1,15 \\
\hline Alagoas & 2.421 & 0,87 & 279.075 & 1.211 & 0,16 & 751.833 & 0,71 \\
\hline Sergipe & 722 & 0,39 & 185.109 & 1.808 & 0,36 & 499.678 & 0,03 \\
\hline Bahia & 7.664 & 0,86 & 889.987 & 12.225 & 0,34 & 3.633 .484 & 0,52 \\
\hline Minas Gerais & 23.404 & 1,00 & 2.330 .894 & 10.516 & 0,34 & 3.116 .716 & 0,66 \\
\hline Espírito Santo & 3.999 & 1,06 & 377.046 & 2.284 & 0,35 & 648.415 & 0,71 \\
\hline Rio de Janeiro & 24.456 & 1,25 & 1.954 .909 & 8.307 & 0,38 & 2.189 .736 & 0,87 \\
\hline São Paulo & 94.285 & 1,37 & 6.893 .664 & 16.389 & 0,39 & 4.153 .396 & 0,98 \\
\hline Paraná & 20.702 & 1,03 & 2.012 .701 & 3.339 & 0,38 & 867.990 & 0,65 \\
\hline Santa Catarina & 15.492 & 1,04 & 1.484 .193 & 673 & 0,26 & 261.288 & 0,78 \\
\hline Rio Grande do Sul & 25.397 & 1,16 & 2.182 .823 & 3.076 & 0,51 & 601.706 & 0,65 \\
\hline Mato Grosso do Sul & 4.102 & 1,27 & 322.808 & 1.641 & 0,44 & 372.873 & 0,83 \\
\hline
\end{tabular}




\begin{tabular}{l|c|c|c|c|c|c|c}
\hline Mato Grosso & 2.231 & 0,78 & 284.404 & 3.573 & 0,57 & 625.057 & 0,21 \\
\hline Goiás & 4.392 & 0,64 & 685.068 & 3.075 & 0,29 & 1.062 .088 & 0,35 \\
\hline Distrito Federal & 4.785 & 1,25 & 384.150 & 4.787 & 0,99 & 485.907 & 0,26 \\
\hline
\end{tabular}

Fonte: Elaboração dos autores, com base nos microdados da PNAD 2013.

A análise de todos os Estados, de todas as regiões do país, permitiu evidenciar as hipóteses levantadas por sociólogos e historiadores sobre a possibilidade de as condições sócio-históricas, articuladas com diferentes configurações étnico-raciais, poderem trazer novos entendimentos sobre como as universidades, em suas respectivas regiões, podem, de forma mais eficiente, ajustar as suas próprias propostas de inserção de negros e de indígenas na pós-graduação, respeitando as suas diferenças socioculturais.

Das 27 unidades federativas, somente em quatro os percentuais de negros (pretos e pardos) superaram os de brancos: Acre (-0,23\%); Amazonas (-0,13\%); Roraima (0,23\%); e Rio Grande do Norte (-0,08\%). Nos demais, os brancos foram majoritários na pós-graduação, mesmo naqueles estados nos quais o total da população branca era menor do que a população negra, como foi o caso da Bahia. Lá, dos 889.987 declarados brancos, registraram-se $0,86 \%$ de estudantes matriculados na pós-graduação. Por outro lado, dos 3.633.484 declarados negros (pretos e pardos), só 0,34\% estavam matriculados nesse mesmo nível de ensino. A diferença entre os brancos e os negros em termos de inserção na pós-graduação chegou a $0,52 \%$. Essa diferença foi altíssima no Amapá $(1,81 \%)$ seguida por Pernambuco $(1,15 \%)$.

Explorando o contexto regional, o Norte do país é uma imensa área de fronteira, sendo que ali não só circulam como passam pessoas de diferentes etnias e de culturas, de línguas diferentes e sem relação nenhuma com o mundo euro-ocidental. Muito possivelmente os autodeclarados como pardos são mestiços, brancos com indígenas, brancos com negros ou negros com indígenas. Nos relatórios da Secretaria de Ensino Superior (BRASIL/MEC/SESU, 2015), as universidades federais do Amapá, do Pará, do Oeste do Pará e a Universidade Rural do Amazonas concederam, cada uma delas, cotas que variaram de $20 \%$ a $40 \%$ para aqueles que se autodeclaram negros ou pardos.

As taxas de matrículas dos negros e das negras na pós-graduação das universidades da região norte suplantam, exceto em Rondônia, todas as taxas dos outros grupos étnicos-raciais. Em contato com colegas da pós-graduação da Universidade 
Federal do Amazonas, tivemos oportunidade de aceder a materiais que apontam pistas que, quem sabe, poderão explicar, em uma outra pesquisa, as razões desses altos indicadores em favor do aumento da população autodeclarada negra nos seus programas de pós-graduação. Visando à internacionalização, o Ministério da Educação (MEC) criou a Universidade Federal do Oeste do Pará (UFOPA), responsável pela expansão amazônica (Brasil, 2009)5. Em termos de registro documental, é, justamente, a Universidade Federal do Pará que vai agregar na pós-graduação o maior número de matrículas com estudantes que se autodeclaram como negros, seguida pela Universidade Federal do Amazonas. Embora essa associação esteja nos dados, será preciso estudos para saber se essas intervenções, visando à ampliação de vagas na pós-graduação aplicadas na região, estão na base desse aumento de percentual de negros e negras nessa modalidade de ensino. Em todo caso, em termos censitários, a taxa de negros nos estados que vão de Rondônia ao Tocantins, passando pelo Amapá, Roraima, Amazonas e Pará, vai de 64,2\% até 78, 4\% de autodeclarados na referida categoria, conforme os dados da Pnad.

Vejamos agora o polo regional oposto. O Sul do Brasil, que abrange Rio Grande do Sul, Santa Catarina e Paraná. Aqui também é uma área de fronteira e a circulação de estrangeiros é grande. Vale lembrar que o Paraná fez parte da província de São Paulo até 1853, quando houve um desmembramento. São Paulo foi parte da região sul até que a ditadura militar decidiu desmembrá-lo e colocá-lo na região sudeste. Mas isso não altera a característica regional que o une aos três estados citados. Todos os quatro compartilham intensamente do movimento de embranquecimento, o qual Sergei Soares identifica como resultado da leva de migração europeia que todos esses quatros estados viveram intensamente, desde o final do século XIX até o fim da primeira metade do século XX. Com exceção de São Paulo, hoje, são esses três estados que formam a região sul na qual os negros são numericamente minoritários, no que se refere às matrículas na pós-graduação.

No rol de universidades federais dessa região que criaram cotas - variando de $20 \%$ a $30 \%$ das vagas - para afrodescendentes encontram-se: a Universidade Federal do

\footnotetext{
${ }^{5}$ Criada pela Lei $\mathrm{n}^{\mathrm{o}} 12.085$, de 5 de novembro de 2009, a instituição é a primeira federal com sede no interior da Amazônia, em Santarém (PA). http://portal.mec.gov.br/component/tags/tag/34305
} 
Paraná; a Universidade Federal do Rio Grande Sul; e a Universidade Federal do Rio Grande, situada no litoral sul do Estado gaúcho. Mas encontram-se cotas também na Universidade Federal de Santa Maria e na Universidade Federal do Pampa.

Na região Nordeste, segundo o IBGE, se encontraria o maior número de negros e negras da população. Conforme as reflexões de Delcele Queiroz (2004), podemos sustentar a hipótese da persistência em manter um número sem muitas rupturas de negras e negros na pós-graduação atribuída às ações afirmativas. Tais ações já vinham sendo praticadas seja por organizações negras, como por exemplo, pela Steve Biko (Cardoso, 2006), ou pelas ações de acadêmicos em suas respectivas universidades fomentando o número crescente nas ações que já vinham sendo desenvolvidas de preparação de negras e negros para ingressar na pós-graduação, por meio dos cursinhos de preparação. Pelo que se pode depreender do documento da SESU (2015), Bahia, Ceará e Pernambuco, no período de 2011 a 2013, tiveram universidades que deram um salto grande no número de negras e negros matriculados na pós-graduação. Ainda, segundo relatório da SESU (2015), a Universidade Federal do Maranhão desenvolve ações afirmativas desde 2007, concedendo $45 \%$ das vagas a quem se autodeclara negro ou pardo. A Universidade Federal da Bahia vai na mesma direção, assim como a Universidade Federal do Recôncavo. Talvez isso explique as altas taxas de matrículas de negras e negros em alguns estados do Nordeste, registradas em 2013. Mas não se pode perder de vista que, quando as comparamos com as dos brancos relacionados com a sua população total, percentualmente, estes são majoritários na pós-graduação.

$\mathrm{Na}$ região Centro-Oeste, a maior diferença percentual de presença a cursos de pós-graduação entre brancos e negros foi registrada no Mato Grosso do Sul, sendo essa diferença de $0,83 \%$ (Tabela 2). Por outro lado, a menor ocorreu no Mato Grosso, tendo apresentado diferença de $0,21 \%$. Ao comparar a inserção exclusivamente dos negros na pós-graduação, o Distrito Federal foi o que apresentou resultado maior e mais satisfatório, equivalente a $0,99 \%$.

Em consulta a documentos acerca das ações afirmativas na UnB, encontramos um relatório que analisa o Sistema de Cotas para Negros da Universidade de Brasília (Rabelo et al., 2015) no qual a própria universidade avaliou o seu sistema de cotas perguntando aos cotistas se eles estavam cursando a pós-graduação stricto sensu. Dos 395 cotistas matriculados, a maioria (57\%) respondeu negativamente. Os outros $43 \%$ 
responderam positivamente, mas somente $16 \%$ deles estavam fazendo pós-graduação stricto sensu (15\% mestrado e $1 \%$ doutorado).

Diferentemente dos outros estados dessa região, o Distrito Federal, desde a sua fundação, conta com a presença maciça de indivíduos provenientes de todas as regiões que têm formas diferenciadas de autodeclarar o seu pertencimento étnico-racial. Lembrando que algumas políticas de ações afirmativas asseguram vagas para afrodescendentes, a questão da autodeclaração passou a ser um dos temas mais polêmicos e com impacto direto na contratação de profissionais para atuar em alguns postos da área pública. Brasília protagonizou, enquanto sede do governo brasileiro, embates acirrados, sobretudo, quando esse tema entrou como critério de seleção no Itamarati, na seleção de candidatos para carreira de embaixador. O pesquisador Ivair Augusto Alves dos Santos (2009), sem desprezar as políticas de ações afirmativas, até mesmo porque esteve na elaboração desse projeto por muito tempo, alertava, a partir de sua posição na Secretaria Nacional dos Direitos Humanos, sobre os cuidados a serem tomados após essa deliberação partindo dos órgãos federais. Uma vez tornado critério de ingresso, muitos jovens brancos que nunca se viram partes do mundo africano, passaram a reivindicar ancestrais dessa origem para disputar cargos em universidades e no Itamarati.

Nesse sentido, Santos (2009) nos alertou para um outro lado do uso da categoria étnico-racial. Pode estar sendo usada não para falar da mudança de posição dos sujeitos na estrutura social, mas, sim, para expressar a usurpação de um direito que não é o dos falsos autodeclarantes.

A última região analisada é a Sudeste. Esta foi a mais estudada pela sociologia no início do século XX, com o intuito de se investigar a mobilização social dos negros na sociedade industrial. Ela concentra o maior número de cursos de pós-graduação e, por consequência, o maior número de matrículas de estudantes. A maior diferença percentual de presença a cursos de pós-graduação entre brancos e negros foi registrada em São Paulo, cuja diferença foi de $0,98 \%$ (Tabela 2). Por outro lado, a menor registrou-se em Minas Gerais, tendo apresentado diferença de 0,66\%. Ao comparar a inserção exclusivamente dos negros na pós-graduação, São Paulo foi o estado que apresentou resultado maior e mais satisfatório, equivalente a $0,39 \%$. 
Tal como ocorreu em outras regiões, conforme dados apresentados do Balanço da SESU 2003-2014, algumas universidades federais passaram a adotar cotas étnicoraciais em seus processos de seleção. Em Minas Gerais, a Universidade Federal do Vale do Jequitinhonha e do Mucuri, a Universidade Federal de Uberaba, a Universidade Federal de Juiz de Fora e a Universidade Federal de São João Del Rey passaram a oferecer $40 \%$ de cotas para quem se autodeclara negro ou pardo. Em São Paulo, a Universidade Federal de São Carlos, a Universidade Federal de São Paulo e a Universidade Federal do Grande ABC, também, passaram a oferecer cotas voltadas para afrodescendentes.

Ressalte-se, foi exatamente nesse período que o Programa Bolsa, realizado pela Fundação Carlos Chagas com o apoio da Fundação Ford, atuou intensamente e uma grande parte dos bolsistas fizeram suas pós-graduações em universidades da região sudeste, com destaque para São Paulo, Rio de Janeiro e Minas Gerais.

\section{CONSIDERAÇÕES FINAIS}

A educação foi, sem dúvida, um campo dentro do qual se estabeleceram conflitos acirrados. E esses embates continuam ocorrendo. Foi possível identificar, com base nos dados oficiais da população brasileira, que os indicadores apontaram o crescimento do número de afro-brasileiros nas escolas em todos os níveis de escolarização. Porém, esse crescimento não garantiu, de forma alguma, que a discriminação e a desigualdade étnico-raciais tenham desaparecido.

Especificamente na pós-graduação, foi identificado que, embora tenha havido aumento da taxa de negros com esse nível de ensino, o crescimento dessa taxa foi ainda maior para as pessoas brancas. Conforme os dados da PNAD, enquanto a taxa de pessoas negras com pós-graduação passou de 0,12\% (2004) para 0,24\% (2013), a de brancos subiu de 0,62\% (2004) para 1,14\% (2013). Embora diminuto para ambos os segmentos étnico-raciais, não se pode negar que a população negra se encontra em desvantagem, embora representasse, em termos demográficos, mais de $50 \%$ da população brasileira.

Entre os estados da federação, os brancos foram majoritários na pós-graduação em quase todos, mesmo naqueles estados nos quais o total da população branca era menor do que a população negra, como foi o caso da Bahia. Somente em quatro das 27 
unidades federativas, os percentuais de negros - pretos e pardos - superaram os de brancos (Acre, Amazonas, Roraima, e Rio Grande do Norte).

A pós-graduação representa a mais alta esfera acadêmica em todas as partes do mundo, carregando grande peso em relação às representações sociais. Diante disso, não dá para não se inquietar com a informação de que esse grupo social tão numeroso - o de negras e negros - ainda encontra enormes dificuldades para aceder ao mundo da ciência. Isso sem levar em conta se existe diferença que seja mais ou menos acentuada quando se considera a área da ciência realizada na pós-graduação.

\section{REFERENCIAS}

AZEVEDO, C. M. M. Onda negra medo branco: o negro no imaginário das elites - século XIX, Rio de Janeiro, RJ: Paz e Terra, 1987.

BENTO, M. A. S. Branqueamento e branquitude no Brasil. In: BENTO, M. A. S.; CARONE, I. (Org.). Psicologia social do racismo: estudos sobre branquitude e branqueamento. Petrópolis, RJ: Vozes, 2002. p. 25-58.

BRANDÃO, A. A.; MARINS, M. T. A. Cotas para negros no Ensino Superior e formas de classificação racial. Educação e Pesquisa, São Paulo, v.33, n.1, p. 27-45, jan./abr. 2007.

BRASIL. Lei $n^{\circ}$ 9.394/1996, de 20 de dezembro de 1996. Estabelece as Diretrizes e Bases da Educação Nacional. Brasília, MEC, 1996.

BRASIL, A democratização e Expansão da Educação Superior no pais 2003-2014, Brasília, MEC/SESu/DIPES, 2015. Disponível em 02/05/2017, in: $<$ http://portal.mec.gov.br/index.php?option=com_docman\&view=download\&alias=16762balanco-social-sesu-2003-2014\&Itemid=30192>

CARDOSO, F. H. Cor Mobilidade Social em Florianópolis - Aspectos das relações entre negros e brancos numa comunidade do Brasil Meridional, São Paulo: Companhia Editora Nacional, 1960

CARDOSO, F. Os Brancos e a Ascensão Social dos Negros em Porto Alegre. Revista Anhembi, ano X, vol. XXXIX, n 117,1960

CARDOSO, F.H. \& IANNI, O. Cor e Mobilidade Social em Florianópolis: Aspectos das Relações entre Negros e Brancos numa Comunidade do Brasil Meridional. São Paulo, Companhia Editora Nacional (Coleção Brasiliana, vol. 307). 1960

CARDOSO, N.M. Instituto Steve Biko - Juventude Negra: mobilizando-se por políticas de afirmação dos negros no ensino superior. Dissertação (Mestrado em Educação) - Universidade do Estado da Bahia, Salvador, 2006.

FUNDAÇÃO CARLOS CHAGAS. Desigualdades de cor/raça e sexo entre pessoas que frequentam e titulados na pós-graduação: 2000-2010. São Paulo: FCC, 2015. Disponível, em 
18/06/2017 em: <http://www.fcc.org.br/fcc/images/pesquisa/pdf/pesquisa-desigualdades-de-core-sexo.pdf

FERNANDES, F. A Integração do negro na sociedade de classe. São Paulo: FFCL/USP, 1964. GONÇALVES, L. A. O. Pensar a educação, pensar o racismo no Brasil. In: FONSECA, M. V. et al. (org.). Relações étnico-raciais e educação no Brasil. Belo Horizonte: Mazza, 2011. p. 93146.

GRISA, G. D.; CAPRARA, B. M. As políticas de ações afirmativas no ensino superior sob a ótica dos gestores: o caso da Universidade Federal do Rio Grande do Sul. Ciências Sociais Unisinos, São Leopoldo, v. 52, n. 2, p. 172-181, maio/ago. 2016.

GUIMARÃES, A. S. Intelectuais negros e formas de integração nacional. Estudos Avançados, São Paulo, v. 18, n. 50, jan./abr. 2004.

EHRINGER, R. Promoção da igualdade racial no Brasil: um objetivo democrático. Tempo e Presença, n. 330, ano 25, p. 285- 311, 2011.

IANNI, O. A ideologia racial do negro e do mulato em Florianópolis, Sociologia, 20 (3), 1958a.

IANNI, O. Estudo da Situação Racial Brasileira. Revista Brasiliense, n 19, SP, 1958b

IANNI, O. O negro da sociedade de castas, Tese de Doutorado, USP - Localização CAPH: 16A - São Paulo 1961

LAMPERT, E. O desmonte da universidade pública: a interface de uma ideologia , Universidade e sociedade, Brasília, Revista Universidade e Sociedade, ano XIV, n. 33, p. 7593, jun. 2004.

MAGALHÃES, A. Trabalho e educação: os efeitos da educação sobre o processo de estratificação social entre brancos e não brancos no Brasil. In: I SEMINÁRIO NACIONAL DE SOCIOLOGIA E POLÍTICA, 1, Curitiba/PR, UFPR, ANAIS, 9, 10 e 11 set, 2009. Disponível, em 23/10/2017, http://www.humanas.ufpr.br/site/evento/SociologiaPolitica/anais/gt9.html

MARIOSA, D. F. Hibridismo e integração nas obras de Florestan Fernandes interpretativas do Brasil, dissertação, Campinas: Unicamp, 2003.

MAUÉS, O. Reforma universitária ou a modernização mercadológica das universidades públicas. Brasília: Revista Universidade e Sociedade ano XIV, n. 33, p p. 22-32, jun. 2004.

MUNANGA, K. Rediscutindo a Mestiçagem no Brasil: identidade nacional versus identidade negra. Belo Horizonte: Autêntica, 2004.

PASCUAL, A. Os caminhos da privatização interna na universidade pública brasileira: o caso das fundações de apoio. Brasília: Revista Universidade e Sociedade , ano XIV, n. 33, p. 68-75, jun. 2004.

QUEIROZ, D. O Negro e a Universidade Brasileira. HAOL, n. 3, p. 73-82, 2004.

RABELO, M.L. et al. Análise do sistema de cotas para negros da Universidade de Brasília: segundo semestre de 2004 ao segundo semestre de 2013. Brasília: UNB, 2015. 
SANSONE, L. Urbanismo, globalização e etnicidade. In: SANSONE, L.; PINHO, O. A. (Org.). Raça: novas perspectivas antropológicas. 2. ed. rev. Salvador: Associação Brasileira de Antropologia/ Edufba, 2008

SANTOS, I. A. A. Direitos humanos e as práticas de racismo: o que faremos com os brancos racistas? 498 f. Tese (Doutorado em Sociologia) - Universidade de Brasília, Brasília, 2009.

SILVA, P. B. V.; SOUZA, G. Relações étnico-raciais e práticas pedagógicas em Educação Infantil. Educar em Revista, Curitiba, n. 47, p. 35-50, jan./mar. 2013.

SOARES, S. A demografia da cor: a composição da população brasileira de 1890-2007. In: THEODORO, Mario (org.). As políticas públicas e a desigualdade racial no Brasil: 120 anos após a abolição. Brasília: IPEA, 2009

SOARES, J. F. Acesso e permanência no Ensino Superior. Brasília: Inep, 2015.

TAFFARELL, C. Z. Morte anunciada: educação superior pública. Brasília: Revista Universidade e Sociedade, ano XIV, n. 33, p. 9-13, jun. 2004.

VOLPI, M.; SILVA, M. S.; RIBEIRO, J. (Coord.). 10 desafios do ensino médio no Brasil: para garantir o direito de aprender de adolescentes de 15 a 17 anos. Brasília, DF: Unicef, 2014. 